\title{
A DESCRIPTIVE STUDY ON SAMM OR NEAR-MISS CASES WITH COMPARISON TO MATERNAL MORTALITIES AND IDENTIFICATION OF THE BARRIERS IN A TERTIARY CARE HOSPITAL IN SOUTH BENGAL
}

\author{
Sandhya Das ${ }^{1}$, Dipankar Gupta², Nibedita Chattopadhyay³
}

${ }^{1}$ Assistant Professor, Department of Obstetrics and Gynaecology, CNMCH, Kolkata, West Bengal, India.

${ }^{2}$ Associate Professor, Department of Paediatrics, SSKM and IPGMER, Kolkata, West Bengal, India.

${ }^{3}$ Associate Professor, Department of Obstetrics and Gynaecology, CNMCH, Kolkata, West Bengal, India.

\section{ABSTRACT}

\section{BACKGROUND}

It is well known that SAMM cases or near-miss cases are defined as those very ill pregnant mothers who would have died, had it not been that luck and good care by her side. ${ }^{1}$ To fight the near-miss cases, prompt diagnosis, proper and meticulous vigilance for every minute is the corner stone of the success to bring the patient out from her death bed.

\section{MATERIALS AND METHODS}

This is a descriptive study, done in The Calcutta National Medical College and Hospital, Kolkata- a tertiary care hospital in South Bengal. The study of SAMM or Near-Miss cases done only on pregnant mothers from 1 ${ }^{\text {st }}$ June 2016 to $31^{\text {st }}$ May 2017.

\section{RESULTS}

135 cases were studied during the period. The main offence detected was the delays, where only $51.80 \%$ could be saved as nearmiss when the critically ill patients had reported after $12 \mathrm{hrs}$. of onset of symptoms. The number of organ system involvement was found directly proportional to the poor outcome.

\section{CONCLUSION}

The objective of this study was actually to identify the barriers responsible for transforming the near-miss cases to maternal mortalities. So that we the obstetricians, the care-givers along with the other resource people could be aware of the situation rightly and obviously in time to avoid the barriers with a determination of "No More Maternal Deaths."

\section{KEY WORDS}

SAMM or Near-Miss Cases, Delays, Organ Dysfunction.

HOW TO CITE THIS ARTICLE: Das S, Gupta D, Chattopadhyay N. A descriptive study on SAMM or near-miss cases with comparison to maternal mortalities and identification of the barriers in a tertiary care hospital in South Bengal. J. Evolution Med. Dent. Sci. 2018;7(30):3377-3379, DOI: 10.14260/jemds/2018/762

\section{BACKGROUND}

We all know that the "Near-Miss" concept is a new launch. The term has come from the Aviation Industry. But here in medical science near-miss is not the air-craft miss, it is a life miss. As noted by Say et al, different types of definitions of near-miss or SAMM (Severe Acute Maternal Morbidity) are found in literature. Ultimately, a standard definition was proposed and was aligned with the International Statistical Classification of Diseases and related Health problems (ICD) 10 th version. Here, a SAMM case is defined as "A woman who nearly died but survived a complication that occurred during pregnancy, at childbirth or within 42 days of termination of pregnancy." To diagnose the case of near-miss we followed minimum 3 criteria, one each from (i) Clinical findings (symptoms and/ or signs), (ii) Investigations and (iii) Interventions done or any single criteria which signifies cardiorespiratory collapse as indicated with Heart symbol, e.g. ICU admission requiring resuscitative or cardio-

'Financial or Other Competing Interest': None.

Submission 14-06-2018, Peer Review 08-07-2018,

Acceptance 14-07-2018, Published 23-07-2018.

Corresponding Author:

Dipankar Gupta,

138A, Sec-A,

Metropolitan Co-Op Housing,

Kolkata-105, West Bengal, India.

E-mail: dipankargupta2005@yahoo.co.in

DOI: $10.14260 /$ jemds $/ 2018 / 762$

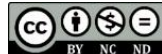

respiratory support; blood and blood products transfusion $>5$ units; use of cardiotonics or vasopressors; circulatory collapse requiring emergency surgery like laparotomy with or without hysterectomy; internal iliac artery ligation, urgent evacuation of uterus etc. - all are to secure haemostasis and thus to reduce further blood loss, which could take mother's life otherwise; and the last but not the least condition for heart symbol is dialysis- peritoneal or haemodialysis. WHO systematic review of literature summarised three distinct approaches of identifying SAMM ${ }^{1}$ - Disease-specific criteria/Intervention Based Criteria/ and Organ dysfunction criteria. Disease-specific criteria use particular disease causing severe maternal mortality. An example is preeclampsia where the occurrence of specific negative sequelae such as convulsions, hepatic involvement etc., signalling the danger of death, but ultimately came out of danger at last causing a maternal near-miss. Intervention-based criteria use admission to an intensive care unit for an obstetrical reason and returned from there out of danger indicating a maternal near-miss. Organ dysfunction criteria use certain markers, such as failure to form clots or the need for a massive transfusion etc., representing a maternal near-miss. The WHO working group suggests the organ dysfunction-based approach is the most promising frame for establishment a standard set of criteria. ${ }^{2}$ Here, in our study we also therefore stressed on organ dysfunction criteria. 


\section{Objectives}

This study was carried out actually to identify the barriers, which were responsible for the failure of the health system to make the case near-miss not of a maternal mortality. So that we can improve our short-comings, aiming at reduction of Maternal Mortality Rate.

\section{MATERIALS AND METHODS}

This study was done at Calcutta National Medical College and Hospital, Kolkata, a tertiary care hospital, at South Bengal in the Department of Gynaecology and Obstetrics.

The patients in majority were referred from peripheral remote areas of South Bengal. 2017.

Study period was one year from $1^{\text {st }}$ June 2016 to $31^{\text {st }}$ May

Number of patients studied was 135 , who presented with life-threatening conditions.

Study design was A Descriptive Study.

\section{RESULTS}

\begin{tabular}{|c|c|c|}
\hline Parameters & Value & $\%$ \\
\hline $\begin{array}{l}\text { I) Total obstetric patients admitted } \\
\text { in study period }\end{array}$ & 16,108 & \\
\hline $\begin{array}{c}\text { II) Total woman with life- } \\
\text { threatening condition studied }\end{array}$ & 135 & 0.83 \\
\hline III) Maternal Near-Miss cases & 84 & 0.52 \\
\hline IV) Maternal Mortality & 51 & 0.31 \\
\hline $\begin{array}{r}\text { Table 1. Incidence of Materno } \\
\text { Maternal Mo }\end{array}$ & $\begin{array}{l}\text { ear-Mi } \\
\text { ity }\end{array}$ & and \\
\hline
\end{tabular}

According to WHO, the prevalence of maternal near-miss case varied between $0.4 \%$ and $8 \%$ in a systematic review of material morbidity and mortality.

In our study, we observed the prevalence of maternal near-miss lying in $0.5 \%$ and that of maternal mortality was $0.3 \%$ during the study period.

\begin{tabular}{|c|c|c|}
\hline Residential Area & Near-Miss (n=84) & Mortality (n=51) \\
\hline Urban & $33(39.28 \%)$ & $04(7.84 \%)$ \\
\hline Rural & $51(60.71 \%)$ & $47(92.15 \%)$ \\
\hline Total & $\mathbf{8 4}$ & $\mathbf{5 1}$ \\
\hline \multicolumn{3}{|c|}{ Table 2. Residential Area of Near-Miss cases and Maternal } \\
Mortality (n=135) \\
\hline
\end{tabular}

Among 135 cases, 98 cases $(51+47)$ had come from a rural background. That means $72.59 \%$ having residence far away from this tertiary care centre in comparison to urban population showing $27.40 \%$. Rural population had higher incidence of mortality due to all types of delays to get lifesaving facilities in time.

\begin{tabular}{|c|c|c|c|}
\hline $\begin{array}{c}\text { Duration of } \\
\text { Delay }\end{array}$ & $\begin{array}{c}\text { Near-Miss } \\
(\mathbf{n = 8 4 )}\end{array}$ & $\begin{array}{c}\text { Mortality } \\
(\mathbf{n = 5 1 )}\end{array}$ & $\begin{array}{c}\text { Total Life- } \\
\text { Threatening } \\
\text { Cases (n=135) }\end{array}$ \\
\hline$<1 \mathrm{hr}$. & 5 & 0 & 5 \\
\hline $1-12 \mathrm{hrs}$. & $36(76.59 \%)$ & $11(23.40 \%)$ & $47(42.22 \%)$ \\
\hline$>12 \mathrm{hrs}$. & $43(51.80 \%)$ & $40(48.19 \%)$ & $83(61.48 \%)$ \\
\hline Total & $\mathbf{8 4}$ & $\mathbf{5 1}$ & $\mathbf{1 3 5}$ \\
\hline \multicolumn{3}{|c|}{ Table 3. Duration of delay in Near-Miss and } \\
Mortality Cases (n= 135) \\
\hline
\end{tabular}

In our study, we observed that $>61 \%$ of study population had reported after 12 hrs. Of onset of symptoms and that among them $48.19 \%$ were in the mortality group, whereas $51.80 \%$ cases only saved as Near-Miss. Majority of cases of Maternal Mortality attended in our facility centre after $12 \mathrm{hrs}$.

\begin{tabular}{|c|c|c|c|}
\hline $\begin{array}{c}\text { Number of } \\
\text { Organ System } \\
\text { Affected }\end{array}$ & $\begin{array}{c}\text { Near-Miss } \\
(\mathbf{n = 8 4 )}\end{array}$ & Mortality & $\begin{array}{c}\text { Total Life- } \\
\text { Threatening } \\
\text { Cases }\end{array}$ \\
\hline 1 & $53(63.09 \%)$ & 0 & $53(39.25 \%)$ \\
\hline 2 & $24(28.57 \%)$ & $3(5.88 \%)$ & $27(52.94 \%)$ \\
\hline 3 & $7(8.33 \%)$ & $6(11.76 \%)$ & $13(9.62 \%)$ \\
\hline 4 & 0 & $11(21.56 \%)$ & $11(8.14 \%)$ \\
\hline 5 & 0 & $31(60.78 \%)$ & $31(28.96 \%)$ \\
\hline Total & $\mathbf{8 4}$ & $\mathbf{5 1}$ & $\mathbf{1 3 5}$ \\
\hline Table 4. Number of Organ System affected in Near-Miss \\
and Mortality (n= 135) \\
\hline
\end{tabular}

This table shows significant differences among the number of organs involved in near-miss and mortality cases. Naturally, the number of organ system found involved is directly proportional to mortality.

\begin{tabular}{|c|c|c|}
\hline Organ System Affected & Near-Miss & Mortality \\
\hline Haematological & 64 & 23 \\
\hline Renal involvement in HTN & 12 & 19 \\
\hline Hepatic involvement in HTN & 9 & 15 \\
\hline CNS & 7 & 2 \\
\hline Respiratory & 5 & 5 \\
\hline Gastrointestinal & 3 & - \\
\hline \multicolumn{3}{|c|}{$\begin{array}{c}\text { Table 5. Details of Organ System affected in Near-Miss and } \\
\text { Mortality (Multiple Response) }\end{array}$} \\
\hline
\end{tabular}

Here, the number of organ system affected is more than the total study population, as a large number of patients had more than one organ system involvement. Haematological system was noted as the most commonly organ affected.

\section{DISCUSSION}

In our study, we followed WHO criteria for selection of cases. The prevalence of maternal near-miss was $0.5 \%$ in this study. ${ }^{3}$ Most of the patients presenting with life-threatening conditions were referred from peripheries. This represents the time lost in coming from one centre to the other. This also reflects poor quality and insufficient primary care which is being administered at first referral centre, losing the valuable time to receive optimal care in time, at first contact, in critically ill patients. There is accumulating evidence that the majority of near-miss cases often arrive in critical conditions in tertiary care centre in developing countries. 4,5,6,7

Study of delays is very important as it will help us to focus on areas which need attention of Government and Policy makers, health workers and service providers with an aim to reduce maternal morbidity and mortality. No studies were found where time duration has been defined. So arbitrary value of $12 \mathrm{hrs}$. was chosen and it was found that delay of $>12$ hrs. doubled the risk of survival. In this study delay 1 (delay to seek care) was the most common delay followed by delay 3 (delay in obtaining care at the facility), while waiting in a queue for long. Very few patients arrived without any delay and all of them had a favourable outcome. Presence of more than one delay was associated with worst prognosis.8,9 The increase in duration of delay, organ systems are irreversibly damaged. Despite advances in diagnostic technology and health programmes for improving antenatal surveillance, 
haemorrhage and pre-eclampsia - eclampsia cases are prevailing and still there are the most common obstetric reasons for critical illness. ${ }^{10}$ In our study also, haemorrhage and pre-eclampsia - eclampsia with HELLP syndrome and/ or renal failure were observed the most notable causes of maternal near-miss or mortality. Sepsis and jaundice had also worse prognosis. Use of blood and blood products was the most common intervention done and were associated with favourable outcome. Inotropic drugs often rescued the patients, though only in first phase of shock. Those needed ventilation and/ or haemodialysis were succumbed to death in majority. In this study, $63.09 \%$ of near-miss cases had only one organ dysfunction; $28.57 \%$ had 2 organ system involvement and only 7 cases had 3 organs affected in comparison to maternal mortality where there were more than one organ system involvement. The aim of this study actually was to audit our health initiatives, frankly speaking our shortcomings. Actually, the drive of resource persons from first referral centre to the facility centre with the help of the authority is the gold standard for bringing out the life of pregnant mothers who was about to die. And this is the only way which help us to curb the maternal mortality and morbidity.

\section{CONCLUSION}

Though the target of, increasing the prevalence of SAMM or Near-Miss cases and at the same time decreasing the maternal mortality rate is the aim in obstetrics, but the target to prevent even the SAMM status is always the corner stone of the health science. Always there is a fear of non-availability and/or the failed system, and consequently again a miss of mother's life. We must admit that every patient is actually a page of a book for teaching. However, one thing is clear in our study that we, the health personnel, must be very much vigilant in every sphere of obstetrics. And, we also must admit that doing a meticulous search, that is interviewing all near-miss survivors, is a yardstick for the identification of the barriers. The last but not the least, the message is definitely the strengthening of peripheral health facilities to curtail the delays to reduce the maternal death.

\section{REFERENCES}

[1] Say L, Souza JP, Pattinson RC, et al. Maternal near miss-towards a standard tool for monitoring quality of maternal health care. Best Pract Res Clin Obstet Gynaecol 2009;23(3):287-96.

[2] MNM - R Form/ Annexure 02, Maternal near miss review operational guidelines. December 2014.

[3] WHO Fact Sheet No 348, May 2012. http://www.who.int/mediacentre/factsheets/fs348/e n/index.html as accessed October 2012.

[4] Puri A, Yadav I, Jain N. Maternal mortality in an urban tertiary care hospital of north India. The Journal of Obstetrics and Gynecology of India 2011;61(3):280-5.

[5] Sivalingam N, Looi KW. Clinical experience with management of "Near-Miss" Cases in obstetrics. Med J Malaysia 1999;54(4):496-503.

[6] Purandare CN. Maternal Near Miss review: a way forward. The Journal of Obstetrics and Gynecology of India 2013;63(4):213-5.

[7] Thaddeus S, Maine D. Too far to walk: maternal mortality in context. Soc Sci Med 1994;38(8):1091110.

[8] Baskett TF, O'Connell CM. Maternal critical care in obstetrics. J Obstet Gynaecol Can 2009;31(3):218-21.

[9] Bashour H, Abdulsalam A, Jabr A, et al. Maternal mortality in Syria: causes, contributing factors and preventability. Trop Med Int Health 2009;14(9):11227.

[10] Adisasmita A, Deviany PE, Nandiaty F, et al. Obstetric near miss \& deaths in public and private hospitals in Indonesia. BMC Pregnancy Childbirth 2008;8:10. 